\title{
Development and Pull-through of Climate Science to Services in China
}

\author{
Chris HEWITT** and Nicola GOLDING \\ Met Office, FitzRoy Road, Exeter EX1 3PB, UK
}

(Received 17 October 2017; revised 24 January 2018; accepted 25 January 2018)

\begin{abstract}
Citation: Hewitt, C., and N. Golding, 2018: Development and pull-through of climate science to services in China. Adv.
\end{abstract} Atmos. Sci., 35(8), 905-908, https://doi.org/10.1007/s00376-018-7255-y.

\section{Introduction}

The impacts arising from climate change and climate variability pose major challenges to global and regional security and economic prosperity (UNFCCC, 2015). Some regions are more at risk than others, through heightened exposure to climatic hazards, and high vulnerability and exposure to such hazards. China, with its rapid economic development, large and growing population, and frequent occurrence of disasters associated with heavy rainfall, flooding, tropical cyclones, heatwaves and drought, is particularly at risk from climate change and climate variability. Climate services, the provision of climate information to assist decision-making, are becoming increasingly important to help address these challenges (Hewitt et al., 2012), and the climate science and climate information that these services are based on is being actively developed and used (Asrar et al., 2012; Hewitt et al., 2016; Vaughan et al., 2017).

Therefore, the China Meteorological Administration (CMA), Institute of Atmospheric Physics at the Chinese Academy of Sciences, and the UK Met Office with UK academic partners have formed the Climate Science for Service Partnership (CSSP China). CSSP China is enabling Chinese and UK scientists to collaborate more closely to develop the climate science and services to help decision-makers in China undertake better informed climate-related risk management across key sectors, including renewable energy, agriculture and food security, urban environments, and air quality. The collaboration is wide-ranging, spanning the development of underpinning science, modeling and observational datasets, the development of prototype climate services, all the way through to close engagement with regional and local climate service providers and their customers, the decision-makers.

This end-to-end approach is already proving effective in helping decision-makers better understand the available climate information and its use and limitations, but also in guiding the development of the underpinning scientific capability to help deliver socioeconomic benefits to the citizens, government and commerce in China (Golding et al., 2017a). The following sections give a brief overview of the science and its link through to services (section 2), progress in the key sectors (section 3 ), and the approach to co-developing prototype climate services in China (section 4).

\section{Science to services}

CSSP China is developing underpinning scientific capability across four broad themes: (1) climate monitoring, attribution and reanalysis to improve understanding of climate and its short- and long-term variations; (2) global dynamics of climate variability and change with the overall aim of improving climate predictions across the region; (3) East Asian climate variability and extremes to improve understanding of regional modes of climate variability, their teleconnections and impacts on the regional water cycle and climate extremes within East Asia; and (4) development of models and climate projection systems to underpin the modeling capability within climate prediction programs.

A fifth theme on climate services integrates across all the activities in CSSP China, drawing on the underpinning scientific capability to develop the more tailored science and services needed to support climate-resilient development and social welfare. This fifth theme has identified key climate-sensitive socioeconomic sectors in China based on CMA's priorities, and is engaging with a selection of users in these priority sectors. The engagement with users is being employed not only to develop the services needed to support decision-making, but through the needs of users informing and guiding further developments of the underpinning scientific capability across CSSP China.

The research and development being undertaken within CSSP China has the potential to be used to help address decisions across a range of temporal and spatial scales, and across different regions of China; plus, the breadth of research and

\footnotetext{
* Corresponding author: Chris HEWITT

Email: chris.hewitt@metoffice.gov.uk 
development across the four scientific themes outlined above affords the potential for a range of different applications.

A specific challenge arising from the development and use of climate information in robust decision-making is the communication, translation and interpretation of climate information. The engagement with users within CSSP China is affording an ideal opportunity to make progress in this area, including co-designing and co-delivering some climate services with close user involvement (Golding et al., 2017b; Hewitt et al., 2017). Such research and development goes beyond the traditional realm of climate scientists by involving social scientists and communication experts.

Additional activities are being undertaken to produce "science for service" handouts (available at https://www.metoffice. gov.uk/research/collaboration/cssp-china) to provide easily communicated information and stories to users and other stakeholders in accessible language, both in English and Mandarin. These handouts highlight new areas of interesting and useful science being undertaken in CSSP China and demonstrate the potential uses of the climate services.

The CMA has developed the China Framework for Climate Services (CFCS; CMA, 2015), a user-oriented service platform acting on the demands of government and customers. The CMA provides climate services based on observations and research findings, and is closely aligned to the Global Framework for Climate Services (Hewitt et al., 2012). The activities in CSSP China are contributing to the implementation and further development of the CFCS. In particular, CSSP China is adopting a sector-based approach, assessing how climate information is being used, and can be used, within the priority sectors, to inform research and development across CSSP China. Trial climate services for key sectors are also being developed, to serve as prototypes for consideration by CMA, for adoption later as operational climate services, and to act as a research tool to understand better the challenges associated with developing and delivering climate services.

\section{Sectoral engagement}

\subsection{Climate services for renewable energy}

Work for the renewable energy sector in CSSP China has so far focused on producing probabilistic seasonal rainfall forecasts for the Yangtze River basin, targeting the rainy season when hydropower requirements are balanced with flood protection activities. Close interaction with decision-makers at hydropower facilities along the Yangtze River, along with a survey eliciting user needs from a wider pool of decision-makers, contributed to a successful trial climate service in 2016 and 2017, disseminated to the CMA for use by operators of hydropower dams for energy production and flood control. Development of the seasonal forecasting system and assessment of the predictability of rainfall for this region of China have supported further development of the climate service, with verification of the trial in 2016, and lessons learned from the trial forming the basis for further discussion and co-development of the service with key users and providers in China (Golding et al., 2017a; 2017b; Bett et al., 2018).

An additional smaller activity has been to undertake research on seasonal wind predictability in regions of China important for renewable wind energy. Initial discussions with users in China in this sector indicated the potential value of a wind forecast for winter in regions with high enough levels of skill, for use in energy infrastructure and wind power prediction. An assessment is now underway to determine whether the climate information requirements of the end users can be met with the current seasonal forecasting capability.

\subsection{Climate services for food security and agriculture}

Work is underway with the Chinese Academy of Agricultural Sciences to progress from theoretical research to applied science, and eventually to a climate service, aimed at informing agricultural and food trade policy in China. Potential climate services for food security and agriculture are considering climatic risk in the present day and potential changes to climatic conditions taking into account climate change. A novel approach has been developed to assess the current and future risk of production shocks for the major crops in China, and to analyze the risk of coincident shocks in other major producing regions of the world (Kent et al., 2017). This work will provide evidence intended to inform long-term planning in agricultural investments for decision-makers at the provincial, regional or national scale in China, with the potential to help ensure the stability of the food system in China in the face of climate change.

\subsection{Climate services for urban environments}

Attention on Chinese cities has mostly focused on weather forecasts for the coming days and early warning systems, but recent initiatives from the Chinese government have emphasized the need for longer term planning for the coming months and beyond, particularly in relation to climate change adaptation and mitigation. In response to this, CSSP China is assessing the potential for climate services for urban environments with a view to designing a prototype climate service later in the project. A scoping study is gaining a better understanding of end-user (such as decision- and policy-makers) requirements for climate information, and identifying the necessary scientific capability to support any climate services. By focusing on the potential users of climate services in Chinese cities, the aim is to provide actionable and useful climate information, and to assess how this information can best be derived from climate prediction and projection systems. 
In addition to the scoping study, the underpinning and applied science to support known user needs is being developed. Convection-permitting models are being developed for urban environments in China and the UK to provide high-resolution extreme temperature and flooding scenarios (at a horizontal resolution of the order of $1 \mathrm{~km}$ ). These simulations of climate variability and change will provide information appropriate for inclusion into future prototype climate services. One particular challenge to managing risk in cities is the large number of interdependent systems at play, only one of which is the climate. A systems-analysis framework for urban climate services is being developed in the context of cities in the Yangtze River Delta, focusing on Shanghai and Hangzhou as case studies. This will help evaluate the cost-effectiveness of several adaptation strategies for these two cities, as well as provide an approach widely applicable in other cities. Finally, collaboration between Chinese and UK scientists is developing sustainable and robust solutions for managing future flood risk under a changing environment in Shanghai, quantifying the compound future flooding risks based on the latest climate and hydrodynamic modelling, conducting reliability analyses of flood defense systems based on coastal and river flood modeling, and assessing losses caused by such compound events.

\subsection{Climate services for air quality}

As with the urban sector, the development of climate services for air quality within CSSP China is more at the stage of scoping user requirements for climate information, and understanding the potential scientific capability to support such services. Attention on air quality in China has traditionally focused on weather forecasting time scales, but recent indications from government ministries in China are that there is a clear need for longer term planning on seasonal and longer time scales. In response to this, as with urban environments, CSSP China is assessing the potential for air quality climate services with a view to designing a prototype climate service later in the project. A scoping study is assessing end-user needs for air quality climate services on time scales of months to decades. This work will recommend potential areas of climate service development, as well as requirements for further underpinning scientific research to support such services. Current underpinning research to support the future development of climate services relating to air quality focuses on the impacts of air quality on agriculture and ecosystems, as well as investigating the impact of emission changes on air quality over East Asia.

\section{Next steps-the development of prototype climate services}

CSSP China is engaging with users on an ongoing basis to continually improve our understanding of their requirements for, and use of, climate information. Such an understanding informs further scientific developments across CSSP China and helps define potential new climate services, or improve existing ones. CSSP China will not develop operational climate services, as these are the remit of the CMA; instead, it is developing a suite of climate service prototypes, or trials. The aims of these prototypes are to: (1) draw together the relevant science from across CSSP China; (2) grow successful collaboration between scientists and climate service providers in the UK and China; (3) demonstrate the pull-through of science to services; (4) increase engagement between providers and users of climate services in China; and (5) support the development of the CFCS. The criteria for selecting the prototypes are that they must be for one of the priority sectors identified in CSSP China, there must be good evidence of user requirements for a climate service, and there must be demonstrated scientific capability to support a climate service.

The development from a broad concept to the co-development of a specific climate service prototype allows us to explore research themes within the climate services landscape-for instance, the processes of co-development, co-production and coevaluation of climate services. The nature of the prototypes means that experience of challenges/failures as well as successes in different approaches can be captured, assessed and shared. A challenge common to most climate service development is the tug-of-war between delivering scientifically credible and robust climate information in which scientists have a sufficient level of confidence, and the user requirements for increased resolution, detail and skill/certainty. The development of prototypes across different temporal and spatial scales, building on a range of scientific capability areas, will allow us to investigate approaches to dealing with such challenges. A theme that will be explored throughout all the prototypes is the translation and communication of complex climate information. In particular, the topic of uncertainty will be explored, and a project is underway to consider the approaches to uncertainty by scientists, producers and users of climate information. This project will support the co-development of prototype climate services and provide more general guidance for the treatment of uncertainty in climate services.

As CSSP China develops over its remaining years there will be opportunities to react to emerging issues in climate science and climate services. In addition, there will be opportunities to consider how to further develop the knowledge and skills of users and providers of climate services in China through capacity development-for example, by training and learning, with a view to improving the provision and uptake of climate services in China and thereby creating a legacy for the outcomes of CSSP China.

On a final note, the activities within CSSP China are designed to complement other activities in China and the UK, as well as broader activities in Europe, Asia, and the global landscape. 
Acknowledgements. This work and its contributors were supported by the UK-China Research \& Innovation Partnership Fund through the Met Office Climate Science for Service Partnership (CSSP) China as part of the Newton Fund.

\section{REFERENCES}

Asrar, G. R., V. Ryabinin, and V. Detemmerman, 2012: Climate science and services: Providing climate information for adaptation, sustainable development and risk management. Current Opinion in Environmental Sustainability, 4, 88-100, https://doi.org/10.1016/ j.cosust.2012.01.003.

Bett, P. E., A. A. Scaife, C. Li, C Hewitt, N.Golding, P. Zhang, N. Dunstone, D. M. Smith, H.E. Thornton, R. Lu and Hong-Li Ren, 2018 Seasonal forecasts of the summer 2016 Yangtze River basin rainfall. Adv. Atmos. Sci., http://doi.org/10.1007/s00376-018-7210-y.

China Meteorological Administration, 2015: China framework for climate service. [Available online at http://www.cma.gov.cn/en2014/ 20150311/2015323e/2015323e07/2015323e09/201503/t20150317_276866.html.]

Golding, N., C. Hewitt, P. Q. Zhang, P. Bett, X. Y. Fang, H. Z. Hu, and S. Nobert, 2017a: Improving user engagement and uptake of climate services in China. Climate Services, 5, 39-45, https://doi.org/10.1016/j.cliser.2017.03.004.

Golding, N., C. Hewitt, and P. Q. Zhang, 2017b: Effective engagement for climate services: Methods in practice in China. Climate Services, 8, 72-76, https://doi.org/10.1016/j.cliser.2017.11.002.

Hewitt, C., S. Mason, and D. Walland, 2012: The global framework for climate services. Nature Climate Change, 2, 831-832, https:// doi.org/10.1038/nclimate1745.

Hewitt, C. D., and Coauthors, 2016: Use of climate predictions to manage risks. WMO-No. 1174, 39 pp.

Hewitt, C. D., R. C. Stone, and A. B. Tait, 2017: Improving the use of climate information in decision-making. Nature Climate Change, 7, 614-616, https://doi.org/10.1038/nclimate3378.

Kent, C., E. Pope, V. Thompson, K. Lewis, A. A. Scaife, and N. Dunstone, 2017: Using climate model simulations to assess the current climate risk to maize production. Environmental Research Letters, 12, 054012.

Vaughan, C., S. Dessai, C. D. Hewitt, W. Baethgen, R. Terra and M. Berterretche, 2017: Creating an enabling environment for investment in climate services: The case of Uruguay's National Agricultural Information System, Climate Services, 8, 62-71.

UNFCCC, 2015: The Paris Agreement. [Available online at http://unfccc.int/paris_agreement/items/9485.php.] 